\title{
SRI CAT Sector 1 Bending Magnet Beamline Description
}

\section{G. Srajer, B. Rodricks, L. Assoufid, and D. M. Mills}

\section{DISCLAIMER}

This report was prepared as an account of work sponsored by an agency of the United States Government. Neither the United States Government nor any agency thereof, nor any of their employees, makes any warranty, express or implied, or assumes any legal liability or responsibility for the accuracy, completeness, or usefulness of any information, apparatus, product, or process disclosed, or represents that its use would not infringe privately owned rights. Reference herein to any specific commercial product, process, or service by trade name, trademark, manufacturer, or otherwise does not necessarily constitute or imply its endorsement, recommendation, or favoring by the United States Government or any agency thereof. The views and opinions of authors expressed herein do not necessarily state or reflect those of the United States Government or any agency thereof.

March 10, 1994

\section{Advanced Photon Source Argonne National Laboratory}




\section{DISCLAIMER}

Portions of this document may be illegible in electronic image products. Images are produced from the best available original document. 


\title{
SRI-CAT Sector 1 Bending Magnet Beamline Description
}

\author{
G. Srajer, B. Rodricks, L. Assoufid and D.M. Mills
}

\section{APS Bending Magnet Source}

Important parameters of the APS bending magnet source are shown in Table 1:

Table 1 Parameters of the APS Bending Magnet Source

\begin{tabular}{|l|l|}
\hline Energy $(\mathrm{GeV})$ & 7.0 \\
\hline Current $(\mathrm{mA})$ & 100.0 \\
\hline Bend Radius $(\mathrm{m})$ & 38.96 \\
\hline Peak Magnetic Field $(\mathrm{T})$ & 0.6 \\
\hline Critical Energy $(\mathrm{keV})$ & 19.5 \\
\hline Flux at Critical Energy & $1.12 \times 10^{13} \mathrm{ph} / \mathrm{s} / 0.1 \% \mathrm{BW} / \mathrm{mradH}$ \\
\hline Horizontal Size $-\sigma_{\mathrm{x}}(\mathrm{mm})$ & 0.11 \\
\hline Vertical Size $-\sigma_{\mathrm{y}}(\mathrm{mm})$ & 0.11 \\
\hline Vertical Divergence $(\mathrm{mrad})$ & 0.073 \\
\hline
\end{tabular}

The front end of the beamline (behind the shield wall) contains a pair of masks that limits the horizontal divergence of the beam to $4.5 \mathrm{mrad}$. Theoretically, the masks can be opened to pass $6 \mathrm{mrad}$ of the beam because the components in the front end are designed to sustain $6 \mathrm{mrad}$. However, in practice, the horizontal mask in the beamline transport on the experimental floor (in front of the white beam hutch) and the size of the transport (6-inch diameter) will limit the beam available for experiments to $3.7 \mathrm{mrad}$.

\section{Beamline Layout}

The bending magnet (BM) beamline of Sector 1 has two experimental stations: a white beam and a monochromatic beam station. In addition, there is a first optics enclosure (FOE), which is an integral part of any APS beamline. According to the adopted nomenclature for labeling stations in the Experiment Hall, the FOE is referred to as 1-BM$\mathrm{A}$, the white beam station as $1-\mathrm{BM}-\mathrm{B}$, and the monochromatic hutch, as 1-BM- C. 
However, the white beam hutch (1-BM-B) is also referred to as the time-dependent studies station and the monochromatic hutch (1-BM-C) as the polarization studies station because of the scientific programs and techniques that are going to be developed in those stations, respectively.

The monochromatic station is designed to operate in the energy range between $6 \mathrm{keV}$ and $24 \mathrm{keV}$ using Si(111) crystal reflection.

Components of the beamline (Fig. 1) and their distance from the source (in meters) are in Table 2.

Table 2 Components of the Beamline

\begin{tabular}{|c|c|}
\hline Component & Distance from the Source (m) \\
\hline Be Window & 22.0 \\
\hline User Filter & 22.5 \\
\hline Horizontal and Vertical Slits & 23.0 \\
\hline Collimator & 23.5 \\
\hline Collimating Cylindrical Mirror & 25.5 \\
\hline Be Window & 26.0 \\
\hline White Beam Diagnostic Screen & 26.5 \\
\hline Double-Crystal Monochromator & 27.0 \\
\hline Monochromatic Beam Diagnostic Screen & 27.5 \\
\hline Be Window & 28.8 \\
\hline Integral Shutter and Beam Stop & 29.5 \\
\hline Be Window & 30.8 \\
\hline Be Window & 35.0 \\
\hline Integral Shutter and Beam Stop & 35.6 \\
\hline Horizontal and Vertical Slits & 37.2 \\
\hline Gate Valve & 41.2 \\
\hline Vertically Focusing Mirror & 42.5 \\
\hline Be Window & 43.5 \\
\hline Photon Beam Position Monitor & 47.0 \\
\hline Be Window & 47.8 \\
\hline
\end{tabular}


The major optical components of the beamline are two cylindrical mirrors and a doublecrystal monochromator, schematically shown in Fig. 2. The ray-tracing diagram of this arrangement is shown in Fig. 3a (top view) and Fig. 3b (side view). Both mirrors are 1.5 $\mathrm{m}$ long. The first mirror, placed $25.5 \mathrm{~m}$ from source, vertically collimates the radiation, while the second mirror, at $42.5 \mathrm{~m}$, does the vertical focusing. Both mirrors have adjustable meridional (or tangential) radius. Horizontal or sagittal focusing is achieved by the bent second crystal in the double-crystal monochromator (DCM). The second crystal in the DCM can also be replaced by a flat crystal.

This configuration for focusing monochromatic radiation was chosen for several reasons:

a. Larger throughput: a cylindrical mirror reflects $75 \%$ of the incoming flux, compared to a toroidal mirror of the same length that reflects only $30 \%$.

b. Higher energy resolution: energy resolution depends only on the intrinsic crystal reflection widths of the DCM; the effect of horizontal divergence on energy resolution is two orders of magnitude smaller.

c. Optimized focusing: horizontal and vertical focusing in the monochromatic station are optimized for all the energies in the range of operation ( $6 \mathrm{keV}$ to $24 \mathrm{keV}$ ). This is not the case for a toroidal mirror, which has a fixed horizontal focus.

d. Greater flexibility: separation of horizontal from vertical focusing allows the users the possibility to select desired focusing schemes. For example, one can eliminate horizontal focusing altogether by replacing a sagittally focusing crystal in the DCM by a flat one.

e. Manufacturing considerations: reliable production of cooled, figured mirrors that are longer than $1 \mathrm{~m}$ has not been yet achieved. On the other hand, flat mirrors bent to a cylinder are much easier and less expensive to fabricate.

Results of ray tracing using SHADOW, shown in Fig. 4, confirm that the combination of two mirrors and a sagittally focusing crystal indeed maximizes the photon throughput without introducing significant optical aberrations.

The slit assembly at $23 \mathrm{~m}$ has an optical aperture of $120 \mathrm{~mm}$ in the horizontal and $30 \mathrm{~mm}$ in the vertical direction. The travel range for the horizontal slits (that define the vertical size of 
the beam) is $30 \mathrm{~mm}$ and is $75 \mathrm{~mm}$ for the vertical slits. The vertical slit resolution is 0.2 $\mu \mathrm{m}$, which enables one to accurately select desired parts of the beam off-axis, an option that may be required in some polarization-type experiments. The horizontal slit resolution is $0.4 \mu \mathrm{m}$. More details of the slit design can be found in the Beamline Standard Components Handbook, January 1994.

\section{Beamline Operation}

The beamline is configured in such a way that the beam is available only in one of the experimental stations at a given time. There is a removable beam transport in the white beam hutch that is put in place when the beam is directed into the monochromatic station. Experiments can be set up in the end station while the beam is available in the white beam hutch. The converse scenario is currently being worked out, because personal safety considerations require additional shielding of both the removable transport and the permanent beamline components inside the white beam hutch.

The BM beamline has two sets of beam transport sizes: 6-inch pipe from the shield wall to the downstream end of the white beam hutch and 4-inch pipe from the end of the white beam hutch to upstream end of the monochromatic station.

Although the first mirror is designed to operate at a fixed incident angle of $2.8 \mathrm{mrad}$, which corresponds to the critical angle for a rhodium-coated mirror for $24 \mathrm{keV}$, there will be cases when mirror adjustments may be required so that the angle of reflection may differ from $5.6 \mathrm{mrad}$. As a consequence, the supports for the beam transport are designed to accommodate such adjustments. The range is $126 \mathrm{~mm}$ or roughly 5 inches.

\section{Beamline Optical Components}

\subsection{Collimating Mirror}

The collimating mirror is the first optical element in the beamline. (See Table 3 for the parameters of the collimating mirror.) Its role is threefold: to vertically collimate the beam, provide harmonic rejection, and to filter the beam and thereby reduce the power load on the monochromator (Fig. 5). 
Table 3 Collimating Mirror Parameters

\begin{tabular}{|l|l|}
\hline Mirror Substrate & GlidCop \\
\hline Mirror Surface & Rhodium \\
\hline Surface Roughness & $3 \AA$ \\
\hline Surface Finish & $2 \mu \mathrm{rad}$ \\
\hline Mirror Location & $25.5 \mathrm{~m}$ \\
\hline Critical Angle & $2.8 \mathrm{mrad}$ \\
\hline Tangential Radius & $18 \mathrm{~km}$ \\
\hline Mirror Length & $1500 \mathrm{~mm}$ \\
\hline Mirror Width & $100 \mathrm{~mm}$ \\
\hline
\end{tabular}

The critical angle is adjustable from $2.5 \mathrm{mrad}$ to $3.5 \mathrm{mrad}$. The tangential radius can be varied from infinity (flat mirror) to $15 \mathrm{~km}$.

Although this mirror is the first optical element in the beamline, a conventional cooling scheme using minichannels and water will suffice in extracting the heat. Power emitted by the BM source per horizontal mrad is $86.7 \mathrm{~W}$. For $3.7 \mathrm{mrad}$ horizontal acceptance, this yields a total power of $321 \mathrm{~W}$. Because the beam is spread over a large area and the incident angle is only $2.8 \mathrm{mrad}$, the peak power density absorbed by the mirror is a manageable $0.005 \mathrm{~W} / \mathrm{mm}^{2}$.

GlidCop was chosen as the substrate because it can be easily machined and polished and has good thermal properties. Rhodium is the choice for a reflective surface because it can be polished to a high degree of surface finish and has strong absorption edges, $23.22 \mathrm{keV}$ (K-edge) and $3.3 \mathrm{keV}$ (M-edge) outside the energy range of interest.

The mirror will be mounted on a holder inside a UHV-compatible vacuum tank. The holder is rigidly attached to the tank, so alignment is achieved by moving the mirror tank. This design was chosen because costly mechanical feedthroughs are eliminated and the cooling manifold for such a long and heavy mirror is greatly simplified. A prototype design is currently being built for the Cornell High Energy Synchrotron Source (CHESS). 
Cooling channels and feedthroughs are designed to have an airguard, so in case of a water leak, there is no direct contact between water and vacuum.

\subsection{Focusing Mirror}

The vertically focusing mirror is placed $42.5 \mathrm{~m}$ away from the source. Its shape is identical to the collimating mirror. However, because most of the power is already filtered by the collimating mirror, the vertically focusing mirror does not require any cooling. It also has a different optimum tangential radius.

The mirror specifications are summarized in Table 4.

Table 4 Focusing Mirror Parameters

\begin{tabular}{|l|l|}
\hline Mirror Substrate & GlidCop \\
\hline Mirror Surface & Rhodium \\
\hline Surface Roughness & $3 \AA$ \\
\hline Surface Finish & $2 \mu \mathrm{rad}$ \\
\hline Mirror Location & $42.5 \mathrm{~m}$ \\
\hline Critical Angle & $2.8 \mathrm{mrad}$ \\
\hline Tangential Radius & $4 \mathrm{~km}$ \\
\hline Mirror Length & $1500 \mathrm{~mm}$ \\
\hline Mirror Width & $100 \mathrm{~mm}$ \\
\hline
\end{tabular}

The critical angle can be varied from $2.5 \mathrm{mrad}$ to $3.5 \mathrm{mrad}$, and the tangential radius from 3 $\mathrm{km}$ to $6 \mathrm{~km}$.

\subsection{Double-Crystal Monochromator}

The double-crystal monochromator (DCM) will provide monochromatic radiation for the polarization studies experimental station. The first crystal is a flat, water-cooled Si (111) crystal, while the second crystal is also Si (111), albeit not cooled, bent to sagittally focus the radiation. The second crystal can also be replaced by a flat one, in case horizontal focusing is not desired. 
Specifications for the DCM are presented in Table 5.

Table 5 DMC Specifications

\begin{tabular}{|l|l|}
\hline Horizontal Beam Acceptance & $100 \mathrm{~mm}(3.7 \mathrm{mrad} @ 27.0 \mathrm{~m})$ \\
\hline Vertical Beam Acceptance & $2 \mathrm{~mm}(0.073 \mathrm{mrad} @ 27.0 \mathrm{~m})$ \\
\hline Vertical Beam Displacement & $35 \mathrm{~mm}$ (fixed exit) \\
\hline Bragg Angle Rotation Range & $14^{\circ}$ \\
\hline Bragg Angle Resolution & $0.0001^{\circ}$ \\
\hline Bragg Accuracy & $0.0004^{\circ}(\mathrm{RMS})$ over $360^{\circ}$ \\
\hline Crystal Orientation & $\mathrm{Si}(111)$ \\
\hline Energy Range & $6 \mathrm{keV}-24 \mathrm{keV}$ \\
\hline Cooling & Water \\
\hline 1st Crystal Surface Area & $110 \mathrm{~mm} \times 110 \mathrm{~mm}$ \\
\hline 2nd Crystal Surface Area & $130 \mathrm{~mm} \times 60 \mathrm{~mm}$ \\
\hline Vacuum Specification & $10^{-6}$ to $10^{-7}$ Torr \\
\hline
\end{tabular}

\section{Time-Resolved Studies Station}

\subsection{General Description}

The Time-Resolved Scattering Program's primary goal is the development of instruments and techniques for time-resolved studies. This program will be carried out primarily from the experimental station 1-BM-B that immediately follows the first optics enclosure (1-BMA). Station 1-BM-B is designated a white beam station. The experimental station is $6.5 \mathrm{~m}$ in length and $5 \mathrm{~m}$ wide (Fig. 6).

The components that reside in 1-BM-A that are of interest to this program are:

1) a vertically collimating rhodium-coated mirror with a cut off energy of $24 \mathrm{keV}$,

2) a double-crystal monochromator that has an option for installing a sagittalfocusing second crystal,

3) an integral white beam shutter and beam stop. 
Station 1-BM-B has the capabilities of accepting from station 1-BM-A the following:

1) monochromatic radiation,

2) pink radiation with the installation of the mirror in the beam,

3) white radiation with both the mirror and monochromator lowered out of the beam.

In both monochromatic and pink beam modes, the integral white beam shutter will be used as the photon shutter, thus minimizing the duty cycle for an experiment by allowing the optical components to be at a constant temperature.

This station will be used for the development of time-resolved $\mathrm{x}$-ray instrumentation and techniques. This entails the development of wide-bandpass optics, high-speed detectors, a mechanical chopper, and components for the measurement and creation of changes in samples (currently, only heating and cooling of samples are being considered). Techniques being developed are pump-probe experiments, single-bunch scattering experiments, and white-and pink-beam Laue scattering. Besides these components that are special to the program, the experimental station will be equipped with the following general purpose instruments:

1) a four-circle 5020 Huber diffractometer,

2) two NaI scintillation detectors,

3) two ionizing chambers for beam normalization,

4) motorized slits, vacuum path, video monitoring,

5) high-speed oscilloscopes (20 GHz equivalent time analog oscilloscope and a 500

MHz digital oscilloscope).

\subsection{Wide-Bandpass Optics}

Two optical systems that will reside in the experimental station are being developed.

1) A curved-crystal monochromator to focus the radiation in the horizontal plane, and

2) a layered synthetic-multilayer monochromator (both flat and figured). 
The optical element that will first be installed in 1-BM-B will be a Si (220) curved-crystal monochromator. The integral shutter and beam stop is designed to allow $3.7 \mathrm{mrad}$ of radiation through to 1-BM-B. With the curved-crystal monochromator being placed 31.5 $\mathrm{m}$ from the source, the $3.7 \mathrm{mrad}$ of horizontal radiation translates into a horizontal beam size of $11.65 \mathrm{~cm}$. The Si (220) crystal is designed to accept $3 \mathrm{mrad}$ of the incident swath. The limits on the energies and ranges available are $6-18 \mathrm{keV}$ with a bandpass from $100 \mathrm{eV}$ to $1000 \mathrm{eV}$. Figure 6 is a top view of the experimental station. The dashed lines are the limits for the two theta for the energies defined above. For higher energies, a smaller swath of the beam will have to be accepted. The monochromator will be in a high vacuum chamber that could be moved to one side to allow the straight through white, pink (by use of the 1-BM-A mirror), or monochromatic (by use of the 1-BM-A double-crystal monochromator) beam into the hutch.

\subsection{Detector Development}

Three detector systems are currently under development:

1) $\mathrm{CCD}$ detectors,

2) CdTe-based photoconductive detectors,

3) Hybrid pixel array detectors.

\section{CCD Detectors:}

The CCD-based detectors are of three types:

1) Large area detectors $(14 \times 14 \mathrm{~cm})$ consisting of $4 \mathrm{CCDs}$ coupled to a fiber-optic taper. This device has a time resolution of $100 \mu \mathrm{sec}$ for multiple exposures, $0.5 \mathrm{sec}$ for one frame, $10 \mathrm{sec}$ for continuous data acquisition.

2) Single CCD devices; either direct $\mathrm{X}$-ray sensitive or coupled to a phosphor with either a lens system or fiber-optic taper. This device has a time resolution of 20 $\mu \mathrm{sec}$ for multiple exposures, $2 \mathrm{~ms}$ for a single row readout, $0.5 \mathrm{sec}$ for a single frame or 8 frames, and $4 \mathrm{sec}$ for continuous data acquisition.

3) High-speed CCD detectors capable of recording in excess of $200512 \times 512$ frames per second. 
CdTe Detectors:

These photoconductive detectors consist of 64 pixels with a pitch of $50 \mu \mathrm{m}$. The pixels are read out in parallel with time resolution in the nsec range for a limited number of frames.

Hybrid pixel array detectors (PADS)

These devices, yet in their early stages of development, would enable us to record eight large area $(10 \mathrm{~cm} \times 10 \mathrm{~cm})$ frames with a time resolution of $1 \mu \mathrm{sec} / \mathrm{frame}$.

All CCD-based detectors are capable of real-time imaging. The CdTe and PADs will be capable of real-time imaging.

\subsection{Chopper System}

To allow one to synchronize the scattering from one positron bunch at a time, a mechanical chopper is being designed. The design under consideration is a rotating disk with a series of holes to allow photons from a single bunch of positrons to pass through. The frequency of this disk will be programmable and synchronized with the data acquisition system, heating system, and temperature measuring system.

\subsection{Sample Stage}

Currently, two mechanisms for heating a sample are under consideration. First, for those samples that do not need to have their temperature changes at high speeds (typical time scale: 0.5 to $1 \mathrm{sec}$ ), a temperature controller for the sample will be available. Second, for pump-probe experiments, a Nd:YAG Q-switched laser with a frequency of $20 \mathrm{KHz}$ will be available for rapid sample heating. A pyrometer will be used for sample temperature measurements.

\section{Polarization Studies Station}

\subsection{Scientific Objective}

The primary program in this station (1-BM-C) is the development of instrumentation and techniques for production and analysis of polarized synchrotron radiation. In particular, the emphasis is given to design of crystal optics that yields: 
(a.) a high degree of circular polarization,

(b.) rapid switching between left- and right-handed circular polarization states, and

(c.) tunability in a wide energy range.

Most of the experiments that use the polarization properties of synchrotron radiation, such as magnetic Compton scattering and magnetic circular dichroism to name a few, are generally flux-limited experiments. However, the performance of crystal optics that manipulate intrinsic synchrotron polarization properties to create desired, high quality polarization states can depend on the brilliance of the source. For example, a crystal optics currently being developed is the thin crystal phase plate, 1,2 in which a small, highly collimated beam can enhance (from calculated $90 \%$ BM source to $99 \%$ Undulator A source) the degree of circular polarization for certain energies. However, many experiments can be successfully performed with $90 \%$ degree of circular polarization. If this ever becomes a limiting factor, the experiment will be moved to an insertion-device beamline.

\subsection{Flux Calculation}

As an example, the available flux at $8 \mathrm{keV}$ is calculated: a $80 \mathrm{~mm} \times 2 \mathrm{~mm}$ slit is set at 23 $\mathrm{m}$, which limits the horizontal divergence to $3.5 \mathrm{mrad}$, while passing all of the $\Omega=0.073$ mrad vertical divergence. Running PHOTON, the calculated flux through the slit is $5.39 \mathrm{x}$ $10^{13} \mathrm{ph} / \mathrm{s} / 0.1 \% \mathrm{BW}$. It is assumed that there is a total of $1 \mathrm{~mm}$ of beryllium in the beamline. At $8 \mathrm{keV}, 82.5 \%$ of the beam is transmitted (Fig. 7). The mirrors reflect $75 \%$ of the incoming flux with $93 \%$ efficiency, which results in $3.10 \times 10^{13} \mathrm{ph} / \mathrm{s} / 0.1 \% \mathrm{BW}$. For 8 $\mathrm{keV}$ and $\mathrm{Si}(111)$ reflection, the Bragg angle is $\theta_{\mathrm{B}}=14.22 \mathrm{deg}$ and the Darwin width $\omega_{\mathrm{S}}=$ 6.92 arcsec or $33.2 \mu \mathrm{rad}$. We consider two cases:

(a) Collimating mirror in place, no beam divergence

The crystal bandwidth is calculated from:

$\frac{\Delta E}{E}=\omega_{s} \cdot \cot \theta_{B}=1.31 \times 10^{-4}$.

Comparing this bandwidth with the bandwidth given for the flux $(0.1 \%)$, i.e., dividing $1.31 \times 10^{-4}$ by 1000 , we obtain 0.131 . Multiplying 0.131 with $3.10 \times 10^{13} \mathrm{ph} / \mathrm{s}$ yields $4.06 \times 10^{12} \mathrm{ph} / \mathrm{s}$. Finally, assuming a conservative $80 \%$ reflectivity for both crystals, the flux at the sample position is $2.60 \times 10^{12} \mathrm{ph} / \mathrm{s}$ in $\Delta \mathrm{E}=1.04 \mathrm{eV}$. 
(b) No collimating mirror

The procedure to calculate the flux is the same as in case (a). The result is also identical. The difference is that the bandwidth is wider:

$$
\frac{\Delta E}{E}=\left(\omega_{s}+\Omega\right) \cot \theta_{B}=4.19 \times 10^{-4}
$$

Thus, the flux is $2.60 \times 10^{12} \mathrm{ph} / \mathrm{s}$ in the bandwidth of $\Delta \mathrm{E}=3.35 \mathrm{eV}$, which is approximately three times larger than $\Delta \mathrm{E}$ with the collimated beam.

\subsection{Station 1-BM-C Description}

The length of the station is $6 \mathrm{~m}$ : the width of the downstream wall is $3 \mathrm{~m}$ and that of the upstream wall is $2.25 \mathrm{~m}$. The departure from the rectangular shape was mandated by the proximity of the 1- $\mathrm{ID}-\mathrm{B}$ (white beam) station and the requirement of at least $1 \mathrm{~m}$ clearance for a corridor between beamlines (Fig. 1). The center of the station is $51 \mathrm{~m}$ away from the source. This station accepts monochromatic radiation only. There are several modes of operation:

(a) Both mirrors and the monochromator are in the beam:

- vertically and horizontally focused beam - second crystal in the DCM is a bent crystal,

- vertically focused beam, horizontally unfocused - second crystal in the DCM is a flat crystal.

(b) Monochromator is in, both mirrors are out:

- vertically unfocused, horizontally focused beam - second crystal in the DCM is a bent crystal.

- unfocused beam - second crystal in the DCM is a flat crystal.

In the case that only the focusing mirror in combination with the monochromator is used, mode (a) of operation is in effect, but with a lesser energy resolution. On the other hand, if only the collimating mirror and the DCM are used, mode (b) becomes an option, however with higher energy resolution. 


\subsection{Station 1-BM-C Hardware}

This station has a 6-circle diffractometer and two motorized optical tables for supporting miscellaneous experimental hardware. Their load capacity is 1000 pounds. The dimensions of the top plate are 5 feet by 3 feet, with a 1-inch-square 1/4-20 tapped hole pattern. The table has 5 degrees of motion, 2 translations, and 3 rotations. The table actuator specifications are:

$\begin{array}{lll}\text { Coarse Vertical Translation } & \pm 3.5 \text { inches } & \text { Manual } \\ \text { Fine Vertical Translation } & \pm 1.0 \text { inches } & \text { Motorized } 10 \mu \mathrm{m} \text { resolution } \\ \text { Fine Horizontal Translation } & \pm 2.5 \text { inches } & \text { - Motorized } 10 \mu \mathrm{m} \text { resolution } \\ \text { Pitch } & \pm 3 \text { degrees } & - \\ \text { Roll } & \pm 6 \text { degrees } & \\ \text { Yaw } & \pm 6 \text { degrees } & \end{array}$

The design of the table that holds the 6-circle diffractometer is currently in progress.

The station is equipped with a gas-handling manifold that allows the experimentalist to use up to four different gasses.

Standard $\mathrm{NaI}$ detectors are available for low-to-medium-resolution experimental requirements. In addition, a high-resolution $\mathrm{Si}(\mathrm{Li})$ solid-state detector is available.

\subsection{Motion Control}

The motion control of the goniometer and all the motorized tables is achieved by using the general-purpose diffractometer scanning software called SUPER, which will be running in the EPICS environment. The motion control hardware supports a total of 24 motors.

\section{Commissioning and Operational Schedule}

The storage ring is scheduled to start with commissioning on January 2nd, 1995. At this time, both the 1-BM-A and 1-BM-B will be ready to accept the beam. In the following 12 months, it is expected that the commissioning of the monochromator, collimating mirror, and both 1-BM-B and 1-BM-C stations will be completed. Finally, the commissioning of 
the focusing mirror should be complete by April of 1996. At this time, the beamline and both experimental stations will be fully operational. In summary, the commissioning plan is as follows:

Beneficial Occupancy of 1-BM-A (utilities, lights, etc.)

Installation of 1-BM-A components complete

Beneficial Occupancy of 1-BM-B (utilities, lights, etc.)

Installation of 1-BM-B components complete

Stations 1-BM- A and B ready for beam (interlocks installed, etc.)

Stations 1-BM-A and B commissioning complete

Monochromator commissioning starts

Collimating mirror commissioning starts

Begin construction of 1-BM-C

Monochromator commissioning complete

Construction of 1-BM-C complete

Station 1-BM-C commissioned

Focusing mirror commissioning starts

Collimating mirror commissioning complete

Focusing mirror commissioning complete
Oct. 1, 1994

Dec. 1, 1994

Dec. 1,1994

Dec. 15,1994

Jan. 2, 1995

Apr. 1, 1995

Apr. 15, 1995

July 1, 1995

Oct. 1, 1994

Sept. 1, 1995

March 1, 1995

June 1,1995

Nov. 1, 1995

Dec. 1,1995

Apr. 1, 1996

\section{References:}

1. V.A. Belyakov and V.E. Dmitrienko, Sov.Phys.Usp. 32, 697 (1989).

2. K. Hirano, T. Ishikawa and S. Kikuta, Nucl.Instrum.Methods 336, 343 (1993).

Acknowledgement: This work was supported by the US Department of Energy, BESMaterials Science under contract no. W-31-109-EN-38. 


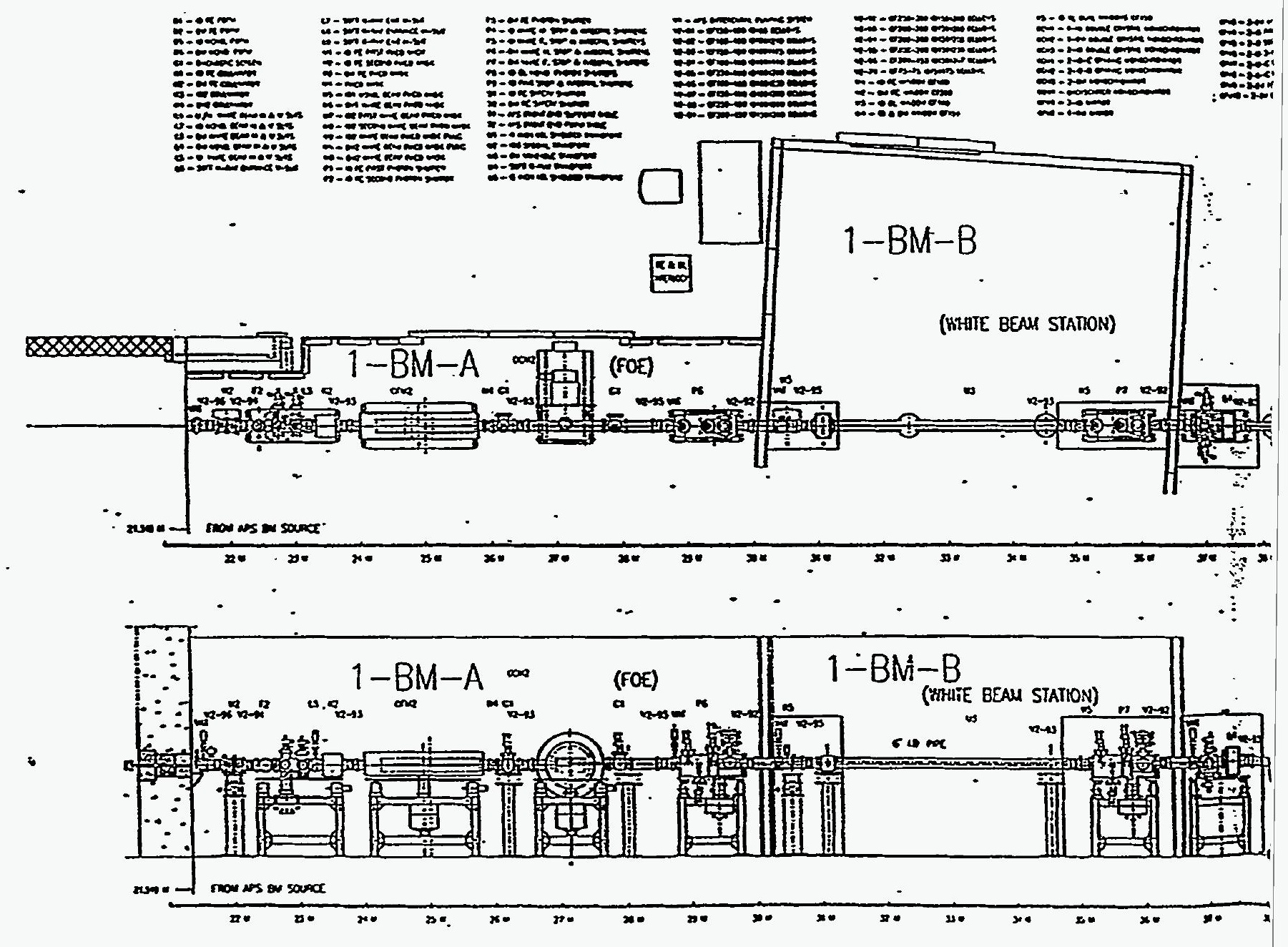

Figure 1 Layout of SRI 


\section{SRICAT BEAM LINE 1-BM-GENERAL LAYOUT DRAFT V.6.0 01-30-1994 BMITS6.OWG S06465}
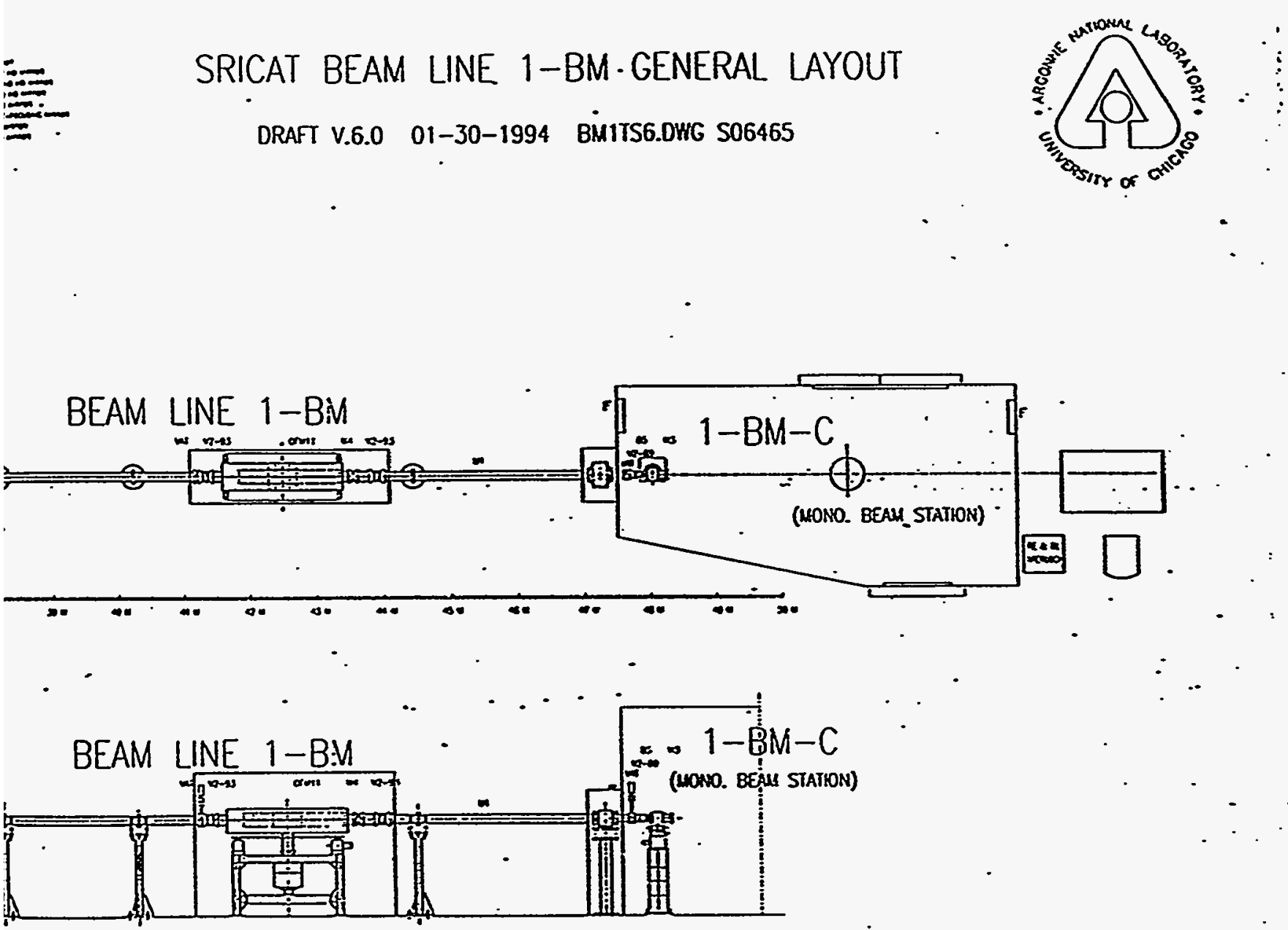

CAT Sector 1 Bending Magnet Beamline 


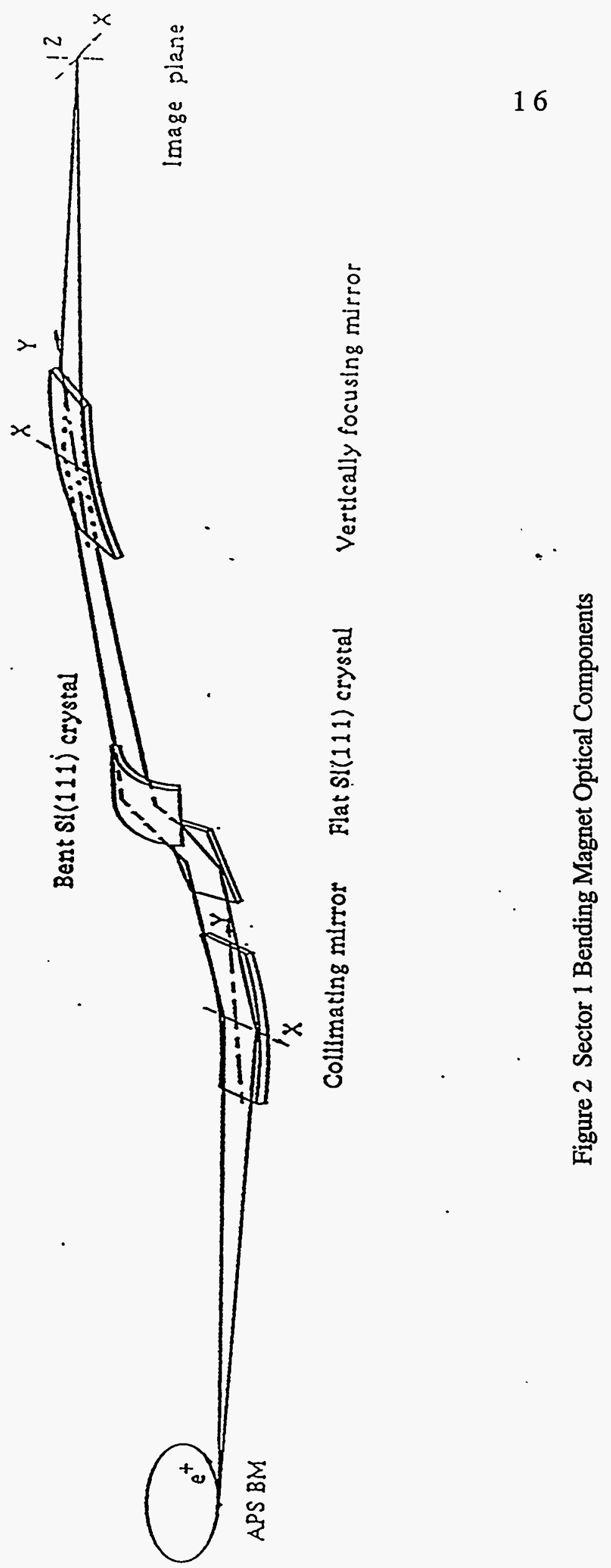




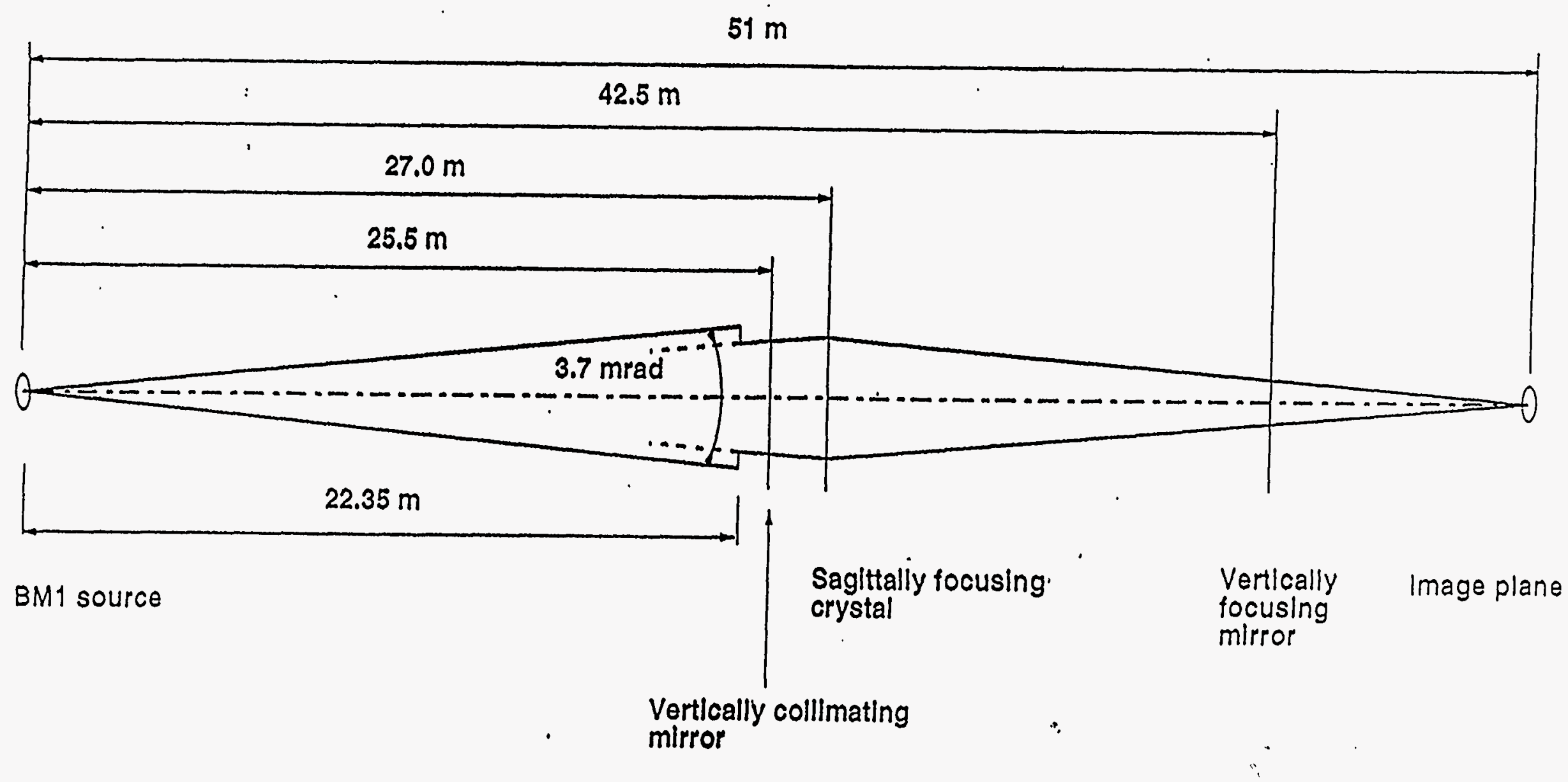

Figure 3(a) 1-BM Beamline Ray Tracing (top view) 


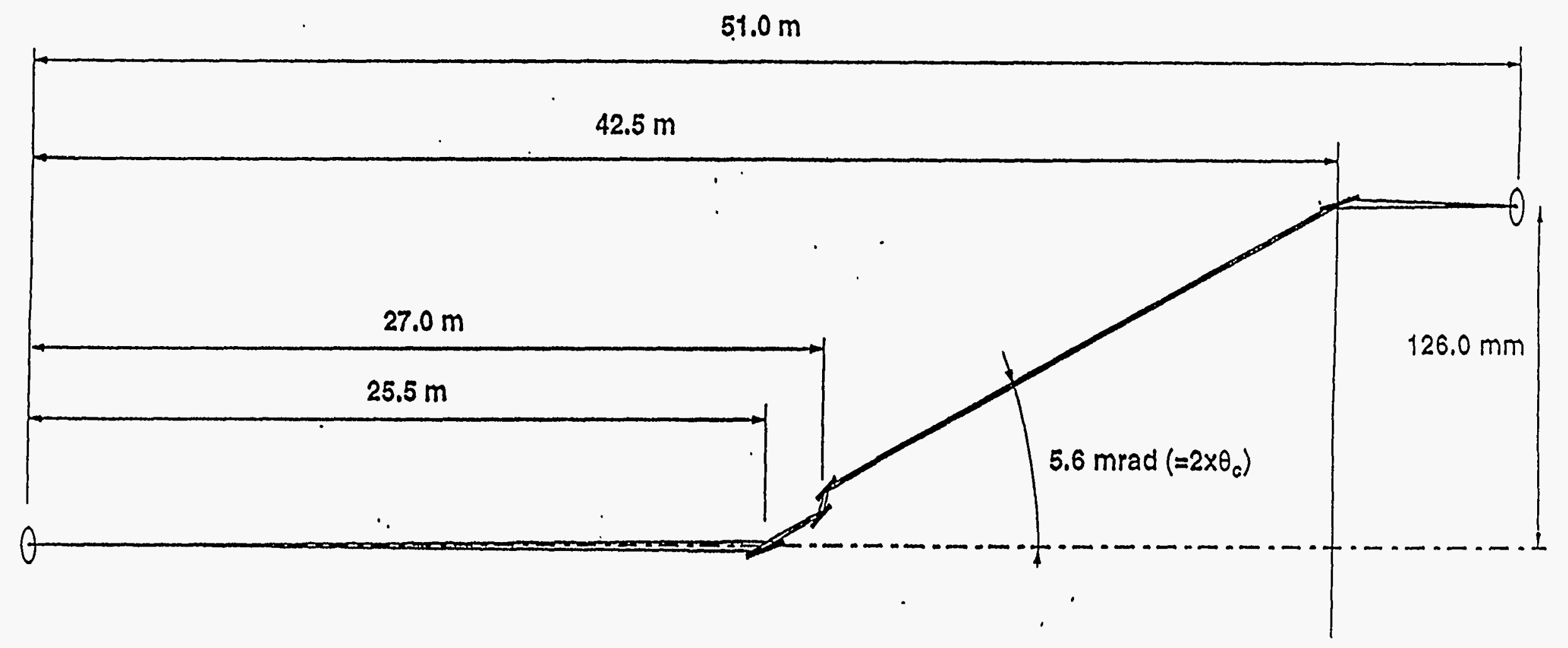

BM1 source

Vertlcally collimating mirror

Sagittally focusing crystal
Vertically focusing mirror 
Figure 4 Ray tracing using SHADOW: (a) beam footprint on the collimating mirror, (b) on the bent crystal, (c) on the focusing mirror and, (d) final image in the 1-BM-C station 51 $\mathrm{m}$ from the source.

(a)

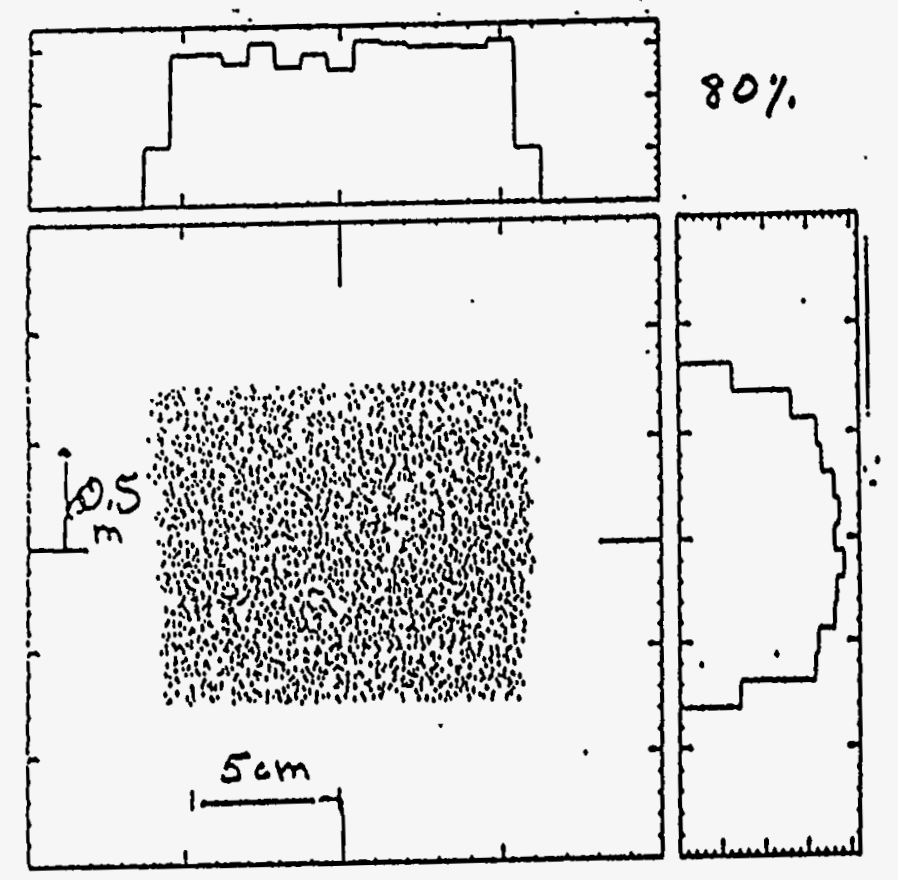

(b)

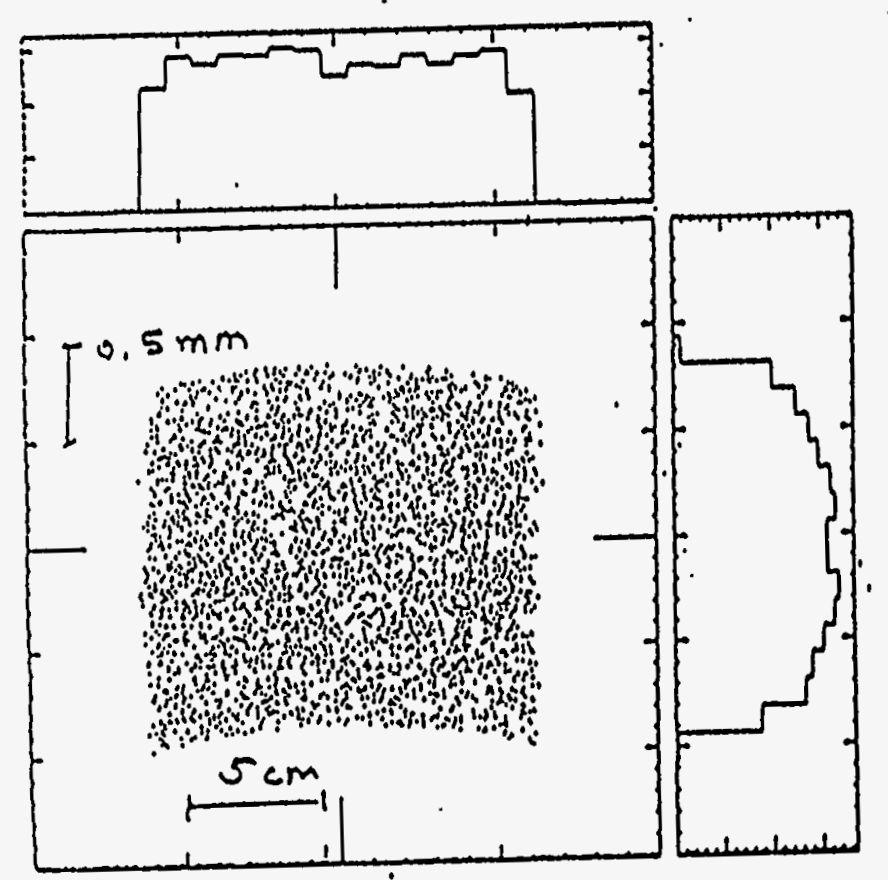

(c)

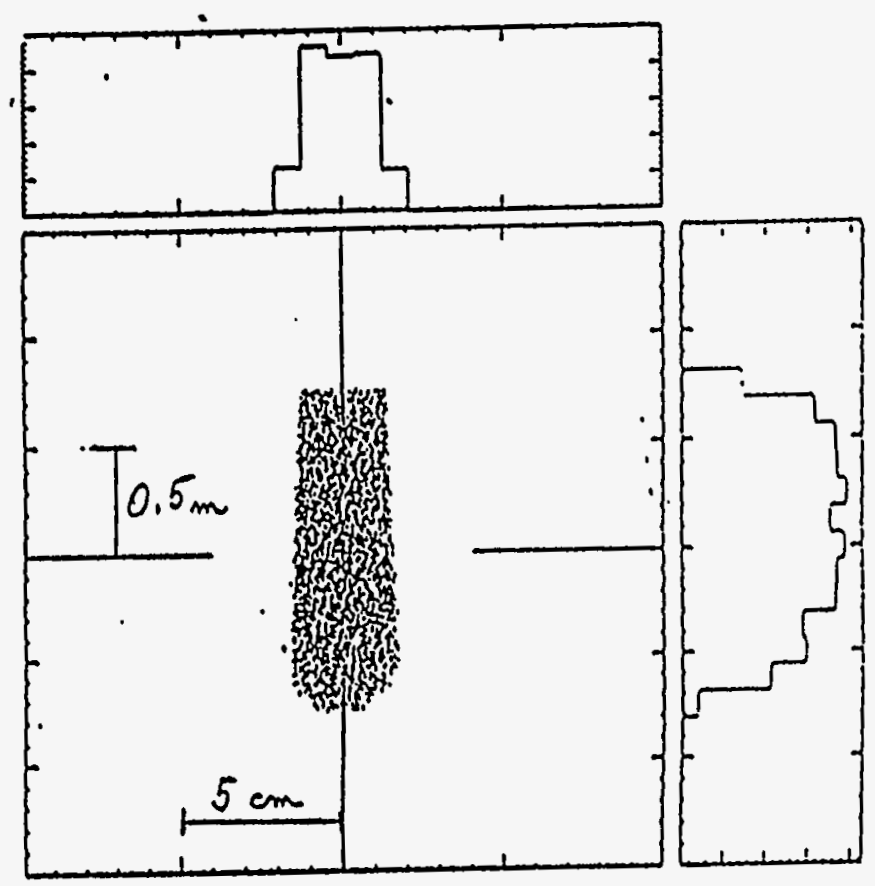

(d)

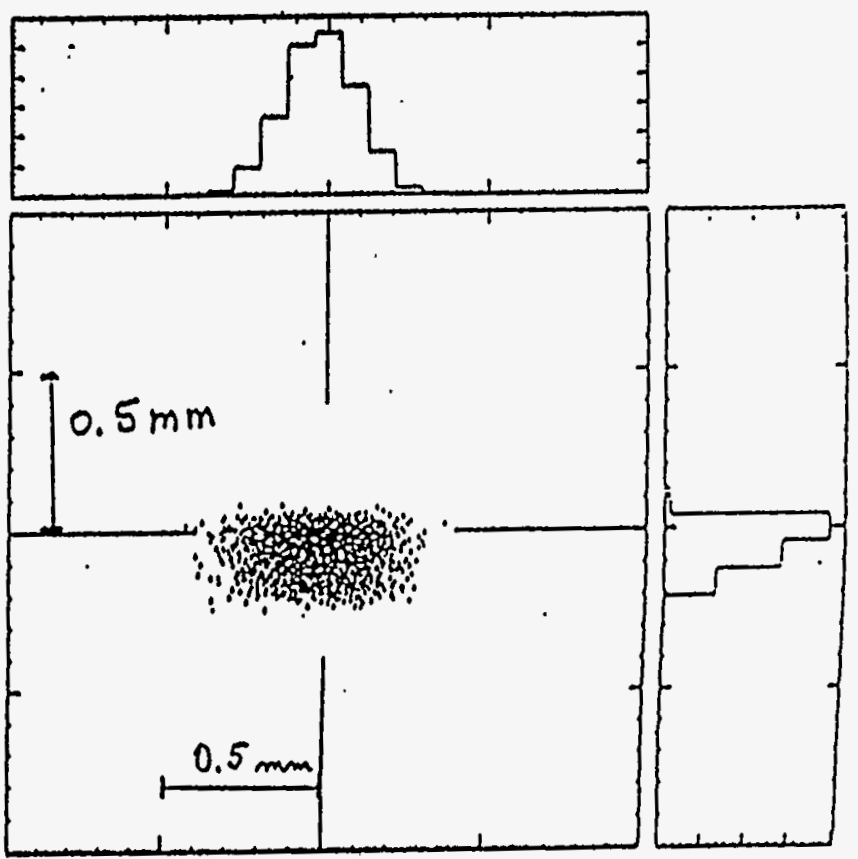




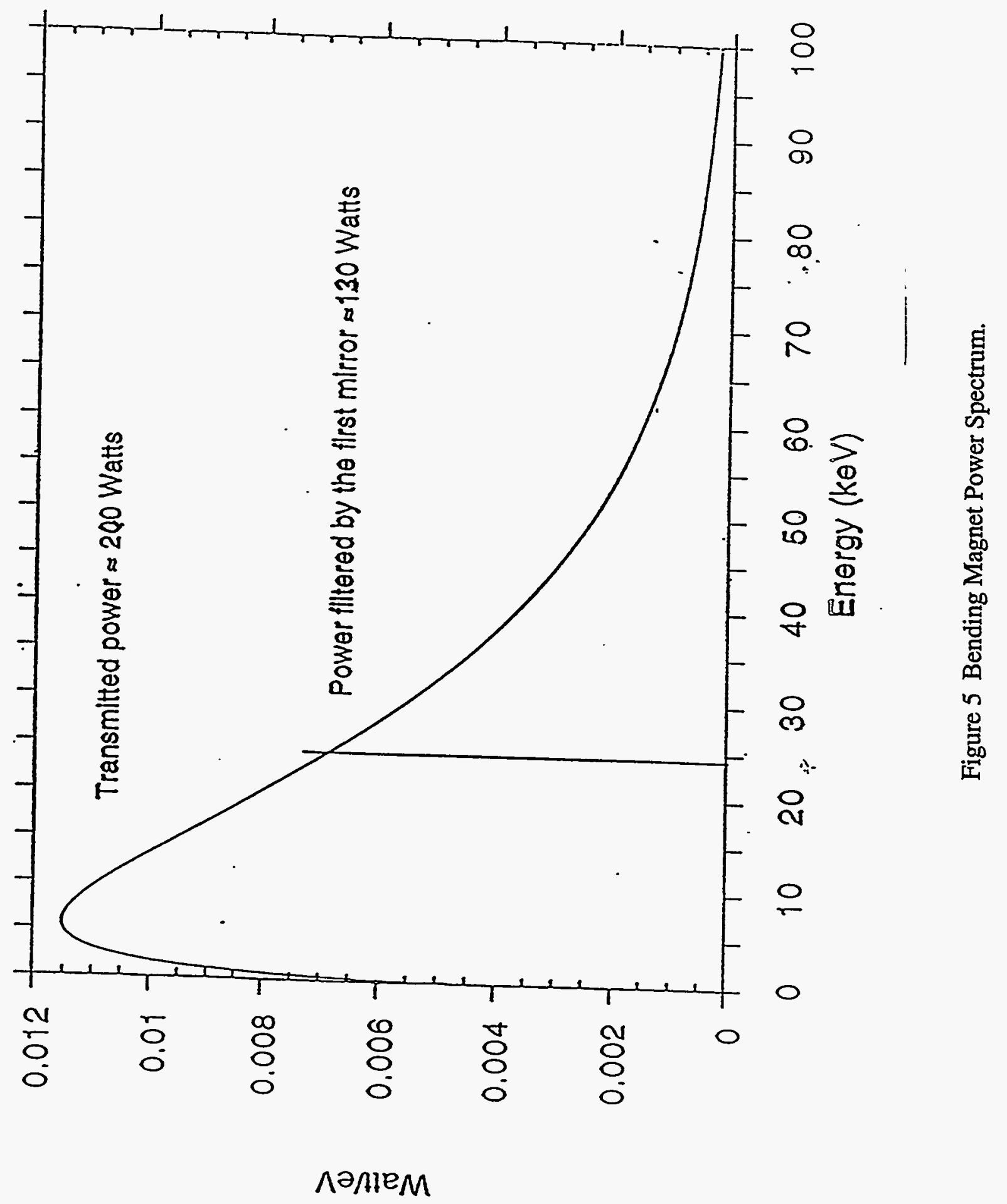




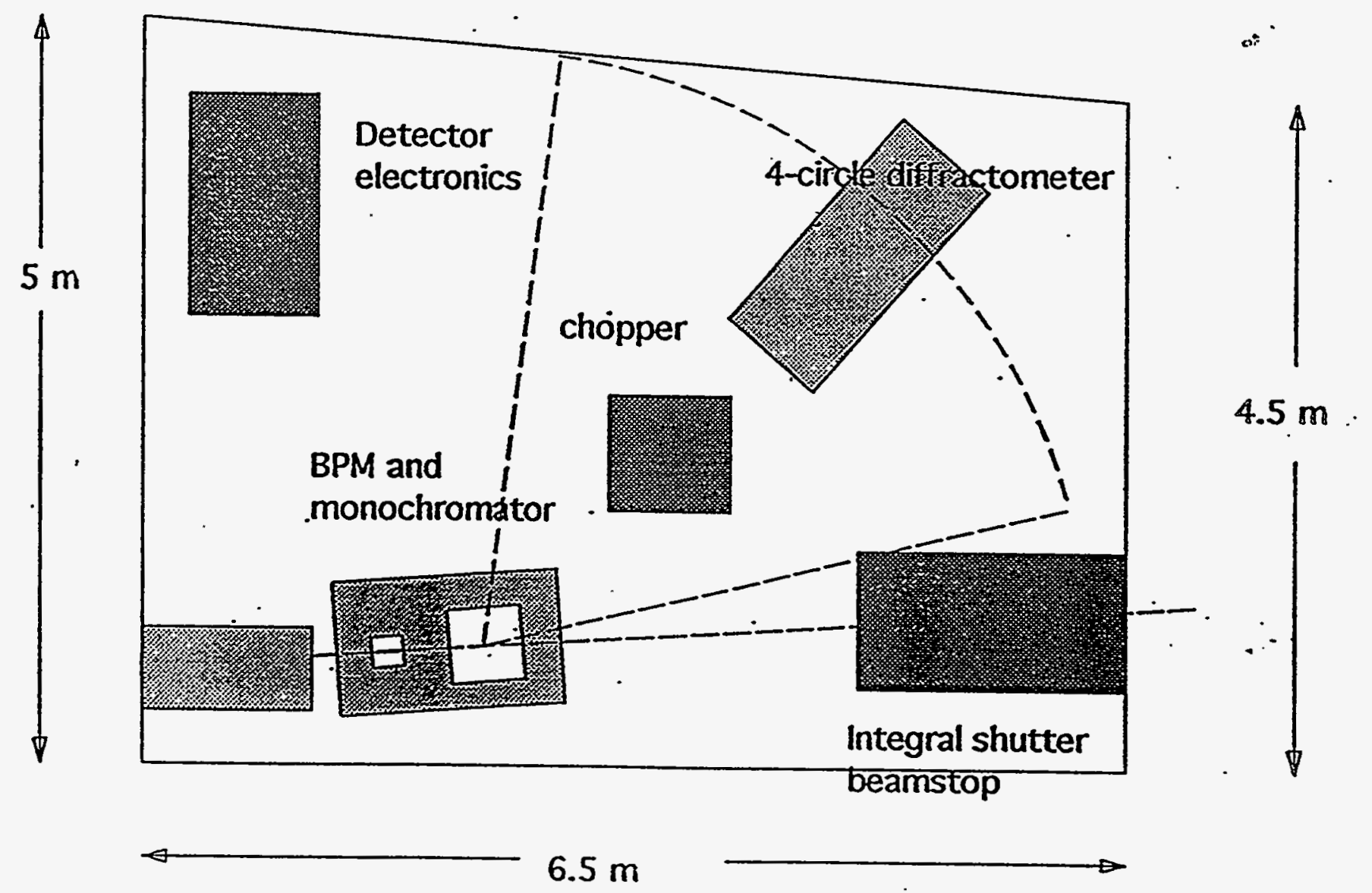

Figure 6 Layout of instruments for white beam station 1-BM-B. 


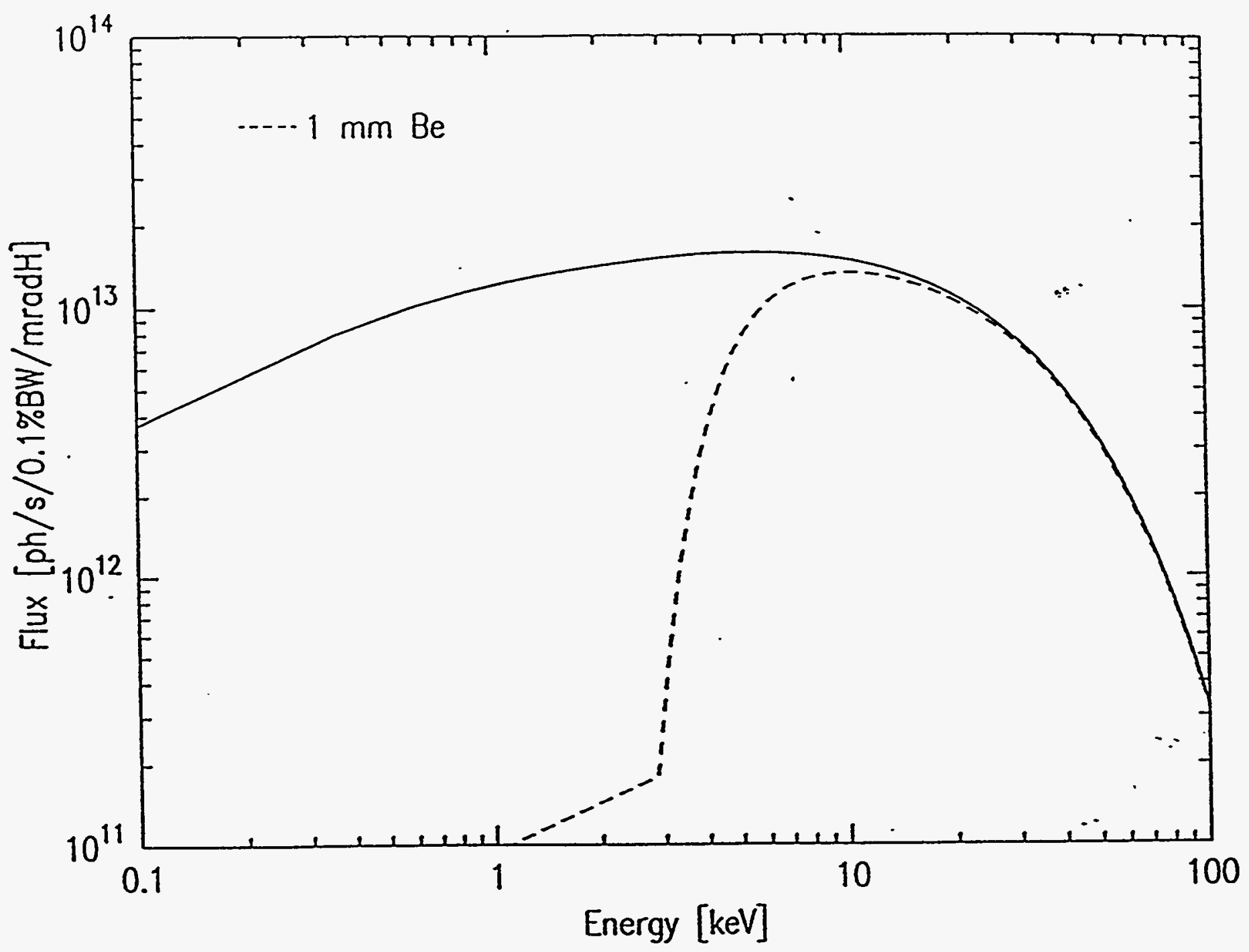

Figure 7 Flux from the APS bending magnet source (solid line) and with $1 \mathrm{~mm}$ of $\mathrm{Be}$ (dashed line. 